Erratum

\title{
Erratum: Polozov, I., et al. Fabrication of Silicon Carbide Fiber-Reinforced Silicon Carbide Matrix Composites Using Binder Jetting Additive Manufacturing from Irregularly-Shaped and Spherical Powders. Materials 2020, 13, 1766
}

\author{
Igor Polozov ${ }^{1, * \mathbb{D}}$, Nikolay Razumov ${ }^{1}$, Dmitriy Masaylo ${ }^{1}$, Alexey Silin ${ }^{1}$, Yuliya Lebedeva ${ }^{2}$ and \\ Anatoly Popovich ${ }^{1}$ \\ 1 Peter the Great St. Petersburg Polytechnic University, Polytechnicheskaya, 29, St. Petersburg 195251, Russia; \\ n.razumov@onti.spbstu.ru (N.R.); dmasaylo@gmail.com (D.M.); silin8888@mail.ru (A.S.); \\ director@immet.spbstu.ru (A.P.) \\ 2 Federal State Unitary Enterprise "All-Russian Scientific Research Institute of Aviation Materials" State \\ Research Center of the Russian Federation, 17 Radio str., Moscow 105005, Russia; yulia.ananieva@gmail.com \\ * Correspondence: polozov_ia@spbstu.ru
} updates

The authors wish to make the following correction to this paper [1]:

Change in Funding.

The authors wish to change the funding part from:

Funding: This research was supported by Russian Science Foundation grant (project No 19-79-30002).

to

Funding: This research received no external funding.

The authors would like to apologize for any inconvenience caused to the readers by these changes.

\section{References}

1. Polozov, I.; Razumov, N.; Masaylo, D.; Silin, A.; Lebedeva, Y.; Popovich, A. Fabrication of Silicon Carbide Fiber-Reinforced Silicon Carbide Matrix Composites Using Binder Jetting Additive Manufacturing from Irregularly-Shaped and Spherical Powders. Materials 2020, 13, 1766. [CrossRef]

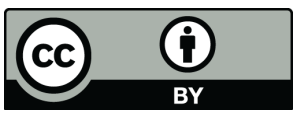

(C) 2020 by the authors. Licensee MDPI, Basel, Switzerland. This article is an open access article distributed under the terms and conditions of the Creative Commons Attribution (CC BY) license (http://creativecommons.org/licenses/by/4.0/). 